\title{
Eine Methode zum Durchschneiden von Seeigeleiern.
}

\author{
Von \\ Karl Peter, \\ Greifswald. \\ Eingegangen am 4. November 1908.
}

Die Durchschneidungsversuche an Seeigeleiern, die ich in Neapel anstellte, mußten leider vor Erlangung sicherer Ergebnisse unterbrochen werden, da die Variationsstudien meine ganze Aufmerksamkeit und Zeit in Anspruch nahmen. Da ich nicht weiß, ob und wann ich diese Experimente wieder aufnehmen kann, so möchte ich im folgenden einen Kunstgriff mitteilen, der die Eier leicht in jeder Richtung za durchschneiden gestattet und, soweit ich sehen konnte, gute Resnltate za liefern verspricht.

Durchschneidungen von Seeigeleiern sind bereits von mehreren Autoren vorgenommen worden. In neuerer Zeit hat N. M. Stevens ${ }^{1)}$ eine gut brauchbare Vorschrift hierfür gegeben und mittels derselben sehr wichtige Resultate erzielt. Doch gestattet diese nicht, die Eier in bestimmter Richtung zu durchschneiden.

Ausgehend von dem Gedanken, die einzelnen Teile der befruchteten und zur Furchung schreitenden Eizelle zu isolieren und ihren Einfluß auf das Protoplasma zu stadieren, suchte ich das Seeigelei in ganz bestimmter Weise zu zerschneiden. Das Stevenssche Verfahren, die Eier auf dem Paraffinüberzug eines Glases zu schneiden, schien mir nach zwei Seiten hin der Verbesserung bedürftig. Einmal rollen die Eier leicht weg und verschieben sich noch unter dem Messer, wodurch eine exakt bestimmte Schnittrichtung nicht zu erreichen ist, und dann ist das Paraffin doch nicht so homogen, alle Einzelheiten des Eiinneren erkennen zu lassen, und ein Material von größerer Durchsichtigkeit ist erwünscht.

1) N. M. Stevens, Experimental Stadies on Eggs of Eehinus microtuberculatus. Areh. f. Entw.-Mech. Bd. 15. 1903. 
Der erste Nachteil ist leicht zu heben. Wenn man nämlich die Eier nach Drieschs bekannter Methode 3-4 Minuten nach der Befruchtung schtittelt, so erhält man stets genïgend viele membranlose Eier, welche dem schneidenden Werkzeng viel weniger ausweichen und eine ganz bestimmte Schnittrichtung erlauben. Ich schnitt mit einer stets frisch geschliffenen Lanzennadel. Da das Schneiden auf Glas selbst sehr schwierig ist - selbst hüllenlose Eier rutschen auf dieser glatten Unterlage leicht fort - war ich darauf bedacht, einen ganz durchsichtigen Überzug über dem Glas anzubringen. Nach vielem Probieren fand ich denselben in einer Celloidinschicht. Ich gieße von einer $4 \%$ igen Celloidinlösung ein wenig in eine flache Schale, so daß eine gleichmäßige dünne Schicht sich auf deren Boden ausbreitet. Nach einer Stunde lasse ich Seewasser einfließen oder lege die Schale in dasselbe. Kurze Zeit darauf (1/4 Stunde etwa) ist das Schälchen gebranchsfertig. Wie mir eigens za dem Zweck angelegte Kulturen zeigten, vertragen die Eier den Aufenthalt in dem Schälchen völlig und entwickeln sich ganz normal. Die Schicht läßt alle Feinheiten des Eies erkennen, auch schneidet sich sehr gut auf ihr. Die Stiucke kleben meist an den Schnitträndern, doch nicht so fest, wie am Paraffin bei dem STEvensschen Verfahren. Ich übertrug sie nach einiger Zeit in kleine Zuchtgläschen zur weiteren Beobachtung. Damit gestaltete sich allerdings die Weiterbehandlung bedeutend komplizierter als bei der oben erwähnten Methode, denn jedes Stiick mußte besonders übergeführt werden. Anderseits gewannen die Teile bald wieder eine runde Gestalt und der deformierende Druck des Paraffins kam in Wegfall. Zu beachten ist noch, daß man das Schälehen ziemlich hoch mit Seewasser anfüllt, damit das schneidende Instrument völlig in dasselbe eintaucht.

Stets suchte ich beide Schnittstiicke zusammen zu behandeln. Naturlich kann man nicht erwarten, in ihnen alle Teile des Eies wiederzufinden; das Messer quetscht mit seiner Schneide von dem kleinen Objekt stets einen Streifen ab, der also in Wegfall kommt. Doch gelang es mir fast stets, die beiden Hälften weiter zu zuchten, so daß mir die Vorschrift empfehlenswert erscheint. 